\title{
Antiproliferative effect of oleuropein in prostate cell lines
}

\author{
ROSARIA ACQUAVIVA ${ }^{1,5^{*}}$, CLAUDIA DI GIACOMO ${ }^{1 *}$, VALERIA SORRENTI $^{1}$, \\ FABIO GALVANO $^{1}$, ROSA SANTANGELO ${ }^{1}$, VENERA CARDILE ${ }^{2}$, SILVIA GANGIA ${ }^{2}$, \\ NICOLANTONIO D'ORAZIO ${ }^{4}$, NADER G. ABRAHAM ${ }^{3}$ and LUCA VANELLA ${ }^{3}$
}

Departments of ${ }^{1}$ Drug Sciences, Section of Biochemistry, and ${ }^{2}$ Bio-Medical Sciences, Section of Physiology, University of Catania, I-95125 Catania, Italy; ${ }^{3}$ Department of Physiology and Pharmacology, University of Toledo College of Medicine, Toledo, OH 43614, USA; ${ }^{4}$ Department of Biochemistry, Human Nutrition Unit, University of Chieti, Chieti; ${ }^{5}$ I.E.ME.S.T., Palermo, Italy

Received January 24, 2012; Accepted March 2, 2012

DOI: $10.3892 /$ ijo. 2012.1428

\begin{abstract}
Currently, there is increasing interest in the in vivo protective effects of natural antioxidants found in dietary plants against oxidative damage caused by free radical species. Oxidative stress has been invoked as a causative agent in cancer and epidemiological data suggest that the consumption of fruits and vegetables may be associated with a lower incidence of cancer. The fruit of the Olea europaea $L$. and olive oil contain hundreds of phytochemicals and its extracts have recently been shown to exhibit antioxidant properties, due to the action of oleuropein. In view of these considerations, in this study, we investigated the effects of oleuropein on LNCaP and DU145 prostate cancer cell lines and on BPH-1 non-malignant cells. Oleuropein reduces cell viability and induces thiol group modifications, $\gamma$-glutamylcysteine synthetase, reactive oxygen species, pAkt and heme oxygenase-1. Exposing cell cultures to oleuropein induces an antioxidant effect on BPH-1 cells and a pro-oxidant effect on cancer cells. Our results confirm the beneficial properties of olive oil and oleuropein, suggesting its possible use as an adjuvant agent in the treatment of prostatitis, in order to prevent the transformation of hypertrophic to cancerous cells.
\end{abstract}

\section{Introduction}

Epidemiological studies have shown that the incidence of atherosclerosis, cardiovascular diseases and certain types of cancer is lower in the Mediterranean area than in other areas $(1,2)$. The

Correspondence to: Dr Luca Vanella, Department of Physiology and Pharmacology, University of Toledo College of Medicine, Health Science Campus, Mail Stop 1008, 3000 Arlington Ave., Toledo, OH 43614, USA

E-mail: vanella@hotmail.it

${ }^{*}$ Contributed equally

Key words: prostate cancer, oxidative stress, oleuropein, heme oxygenase-1, $\gamma$-glutamylcysteine synthetase, Akt lower rate of large bowel, breast, endometrial, as well as prostate cancers, described by a number of epidemiological studies, besides possible genetics factors, is also attributed to the characteristic type of diet of the local population. The Mediterranean diet, unlike that of Northern Europe and America, is characterized by a high consumption of vegetables, cereals, fruit, fish, wine and olive oil. The beneficial effects of the Mediterranean diet against cardiovascular diseases and cancer have been attributed to the natural antioxidants contained therein, particularly ascorbic acid, tocopherols, $\beta$-carotene, anthocyanins and other polyphenols (3-7). A number of studies have reported a direct correlation between total phenolic content and antioxidant activity in fruits and vegetables (6,7).

Since olive oil is the major energy source in the Mediterranean diet, several studies were recently conducted on the beneficial effects of olive oil, a product extracted mechanically from olives, the fruit of Olea europaea $L$. (Oleaceae family) $(8,9)$. Olea europaea $L$. is native to the Mediterranean basin and parts of Asia Minor. Its fruit, the olive, and olive oil have a wide range of therapeutic and culinary applications. Historically, the products of Olea europaea L. have been used as aphrodisiacs, emollients, laxatives, sedatives and tonics. Specific conditions traditionally treated include colic, alopecia, paralysis, rheumatic pain, sciatica and hypertension (10).

A number of studies have reported that olive oil is more effective against cancer than other forms of added lipids, due to its high content of monounsaturated fatty acids $(8,9,11)$. A diet containing $15 \%$ olive oil has been shown to significantly reduce pre-cancerous lesions in rat breast and colon $(12,13)$. However, similar amounts of soy oil do not have such a protective effect (14). Furthermore, a previous study showed that the incidence of breast cancer was $70 \%$ less in the rat group fed olive oil than in the group fed safflower oil $(8,9)$. These data suggest that the cancer preventive effect of olive oil is not only due to its 'good' fat content but also recent evidence suggests that minor compounds in olive oil may play a role in cancer protection, focusing attention on its phenolic compounds. These properties are also attributed to the phenolic compounds of olive leaves. Currently, there is an increasing interest in the phenolic compounds in olive by-products, due to their biological properties. Olive oil polyphenols show beneficial antioxidant activities $(15,16)$. These 
compounds are a consequence of the reaction of the olive tree to pathogen attack and its response to insect injuries.

There are five groups of phenolic compounds principally present in olive leaves: oleuropeosides (oleuropein, verbascoside), flavones (luteolin-7-glucoside, apigenin-7-glucoside), flavonols (rutin), flavan-3-ols (catechins) and substituted phenols (tyrosol, hydroxytyrosol, vanillin) (10).

The most abundant compound in olive leaves is oleuropein, followed by hydroxytyrosol, the flavone-7-glucosides of luteolin and apigenin, and verbascoside (17). Oleuropein, discovered in 1908 by Bourquelot and Vintilesco, is a heterosidic ester of elenolic acid and dihydroxyphenylethanol $(17,18)$. Oleuropein, is the major constituent of the secoiridoid family. Upon hydrolysis, oleuropein can produce other bioactive substances, namely eleonolic acid and hydroxytyrosol. Oleuropein is present in high amounts in unprocessed olive fruit and leaves, while hydroxytyrosol is more abundant in processed olive fruit and olive oil.

A number of studies have shown that oleuropein possesses a wide range of pharmacological and health promoting properties including antiarrhythmic, spasmolytic, cardioprotective, hypotensive and anti-inflammatory properties $(19,20)$. It has been shown that oleuropein prevents cardiac disease by protecting membranes from lipid oxidation, affecting coronary blood vessel dilation, exerting antiarrhythmic action and improving lipid metabolism $(17,21)$. It has been suggested that many of these properties are a result of its antioxidant character $(19,20)$.

In vivo and in vitro studies on the activity of oleuropein have found that it has antiangiogenic action and is able to inhibit tumour cell growth and invasiveness $(22,23)$. However, many of the in vitro studies were performed solely with cells derived from malignant tissues; instead, an important aspect of the present study was the comparative responses of normal and malignant cells to the test agents. The effect of oleuropein was tested on LNCaP and DU145, two different human prostate cancer cell lines which represent two different stages of the disease, and on BPH-1, a non malignant cell line.

\section{Materials and methods}

Chemicals. Polyclonal $\gamma$-glutamylcysteine synthetase $(\gamma$-GCS) antibody was obtained from Abcam (Victoria, BC, Canada). Secondary horseradish peroxidase-conjugated anti-rabbit antibody was from Santa Cruz Biotechnology (Santa Cruz, CA, USA). The Enhanced Chemiluminescence System for developing immunoblots and nitrocellulose membranes were purchased from Amersham (Milan, Italy). The ELISA kit, used to measure heme oxygenase-1 (HO-1) protein concentration, was from Stressgen Biotechnologies (Victoria, BC, Canada). The Upstate pAKT 1 kit, used to measure pAKT(Thr308) and pAKT(Ser473), was from Millipore (Billerica, MA, USA). 3(4,5-dimethylthiazol-2-yl)2,5-diphenyl-tetrazolium bromide (MTT) and 2',7'-dichlorofluorescein diacetate (DCFH-DA) were obtained from Sigma Aldrich Co. (St. Louis, MO, USA). All other chemicals were purchased from Gibco-BRL Life Technologies (Grand Island, NY, USA).

Cell culture and treatments. Benign prostate hyperplasia epithelial cells (BPH-1) were grown in RPMI-1640 medium supplemented with $10 \%$ fetal calf serum, $1 \mathrm{mM}$ glutamine and $10 \mu \mathrm{l} / \mathrm{ml}$ penicillin-streptomycin.

Human prostate cancer androgen-responsive LNCaP and androgen non-responsive DU145 cells were purchased from the American Type Culture Collection (ATCC, Rockville, MD, USA). The LNCaP cell line was grown in RPMI-1640 medium supplemented with $10 \%$ fetal calf serum, $1 \mathrm{mM}$ glutamine and $10 \mu \mathrm{l} / \mathrm{ml}$ penicillin-streptomycin. DU145 cells were maintained in Earle's Minimal Essential Medium (EMEM), containing $10 \%$ fetal calf serum, $1 \mathrm{mM}$ glutamine, antibiotics (50 IU/ml penicillin and $50 \mu \mathrm{g} / \mathrm{ml}$ streptomycin) and $1 \%$ nonessential amino acids.

The cells were plated at a constant density to obtain identical experimental conditions in the different tests, thereby ensuring high accuracy of the measurements. After 24-h incubation at $37^{\circ} \mathrm{C}$ under a humidified $5 \% \mathrm{CO}_{2} / 95 \%$ air mixture to allow cell attachment, the cells were treated with different concentrations of oleuropein (100-500 $\mu \mathrm{M})$, and incubated for $72 \mathrm{~h}$ under the same conditions. Four replicates were performed for each sample.

MTT bioassay. To monitor cell viability, the cells were plated at $8 \times 10^{3}$ cells per well of a 96-multiwell flat-bottomed $200 \mu \mathrm{l}$ microplate (24). The optical density of each well sample was measured with a microplate spectrophotometer reader (Titertek Multiskan, Flow Laboratories, Helsinki, Finland) at $\lambda=570 \mathrm{~nm}$.

Lactic dehydrogenase release. Lactate dehydrogenase (LDH) release was measured to evaluate the presence of cell necrosis as a result of cell disruption, subsequent to membrane rupture. LDH activity was measured spectrophotometrically in the culture medium and in the cellular lysates, at $\lambda=340 \mathrm{~nm}$ by analyzing NADH consumption (24).

The percentage of LDH release was calculated as the percentage of the total amount, considered as the sum of the enzymatic activity present in the cellular lysate and that in the culture medium.

Thiol group determination. Thiol groups were measured by using a spectophotometric assay as previously described (25). Results are expressed as $\mu \mathrm{mol} / \mathrm{mg}$ protein. Protein concentration was measured according to the method described by Bradford (26).

Reactive oxygen species (ROS) assay. Determination of ROS was performed by using a fluorescent probe 2',7'-dichlorofluorescein diacetate (DCFH-DA), as previously described (27). The fluorescence [corresponding to the oxidised radical species 2',7'-dichlorofluorescein (DCF)] was monitored spectrofluorometrically (excitation, $\lambda=488 \mathrm{~nm}$; emission, $\lambda=525 \mathrm{~nm}$ ). The total protein content was evaluated for each sample, and the results are reported as percentage increase in fluorescence intensity/mg protein with respect to control (untreated) cells. Protein concentration was measured according to the method described by Bradford (26).

Western blot analysis. BPH-1, DU145 and LNCaP cells were harvested using cell lysis buffer, the lysate was collected for western blot analysis and protein levels were visualized by immunoblotting with antibody against $\gamma$-GCS as previously described (24). 
HO-1 measurements. A commercially available enzyme-linked immunosorbent assay (ELISA) kit was used to measure HO-1 protein concentration in cellular lysates. The assay was performed in accordance with the protocol provided by the manufacturer.

Absorbance at $\lambda=450 \mathrm{~nm}$ was measured and HO- 1 concentration was calculated from a standard curve generated with purified HO-1 (28). The limits of detection provided by the manufacturer were $0.78-25 \mathrm{ng} / \mathrm{ml}$. Results are expressed as $\mathrm{ng} /$ mg protein. Each measurement was performed in triplicate and averages were reported.

Akt/PKB measurements. A commercially available Upstate colorimetric Signal Transduction Assay Reaction (STAR) ELISA kit was used to measure phospho-Akt(Thr308) and phospho-Akt(Ser473) in cellular lysate. The assay was performed in accordance with the protocol provided by the manufacturer (29).

The absorbance was measured at $\lambda=450 \mathrm{~nm}$ using a plate reader, and p-Akt(Thr308) and p-Akt(Ser473) concentrations were calculated from a standard curve. The limits of detection provided by the manufacturer were $0.3-2 \mathrm{ng} / \mathrm{ml}$. Each measurement was performed in triplicate and averages were reported. Results are expressed as U/ng total Akt.

Statistical analysis. One-way analysis of variance (ANOVA) followed by Bonferroni's t-test was performed in order to estimate significant differences among groups. Data are reported as mean values \pm SD and differences between groups were considered to be significant at $\mathrm{p}<0.005$.

\section{Results}

Effects of oleuropein on BPH-1, LNCAP and DU145 cell viability. MTT assay was performed to monitor cell viability, measuring the conversion of tetrazolium salt to yield colored formazan, the amount of which is proportional to the number of living cells. The treatment of BPH-1, LNCaP and DU145 cells with 100-500 $\mu \mathrm{M}$ oleuropein for $72 \mathrm{~h}$ resulted in a significant reduction in cell viability, particularly evident in $\mathrm{LNCaP}$ and DU145 cells (Fig. 1).

The results showed a dose-dependent inhibitory effect on succinate dehydrogenase activity, the major mitochondrial enzyme responsible for the MTT formazan conversion, with high concentrations (100-500 $\mu \mathrm{M})$ of oleuropein, whereas low (5-50 $\mu \mathrm{M})$ concentrations did not modify cell viability (data not shown).

$L D H$ release. Necrosis results in a distruption of cytoplasmic membrane with the consequent release of cytoplasmic LDH into the medium. We therefore examined the membrane integrity and hence the rate of necrosis in the treated cells by determining the percentage of $\mathrm{LDH}$ activity released into the culture medium.

As shown in Fig. 2, the presence of $100 \mu \mathrm{M}$ oleuropein in the culture medium did not significantly change LDH release in BPH-1 and LNCaP cells, whereas the same dosage caused a significant increase of LDH release in DU145 cells. The highest oleuropein concentration $(500 \mu \mathrm{M})$ induced necrosis in all three cell types, although it was more efficient in DU145 cell line.

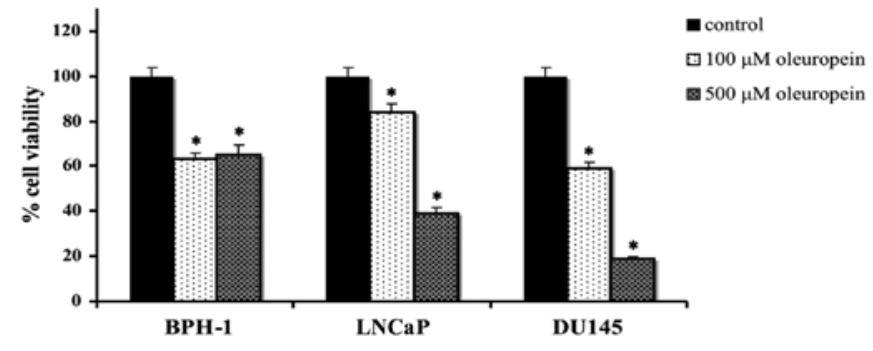

Figure 1. Cell viability in BPH-1, LNCaP and DU145 cells untreated and treated for $72 \mathrm{~h}$ with oleuropein at different concentrations $(100-500 \mu \mathrm{M})$. Values represent the means \pm SD of four experiments performed in triplicate *Significant vs. untreated control cells: $\mathrm{p}<0.001$.

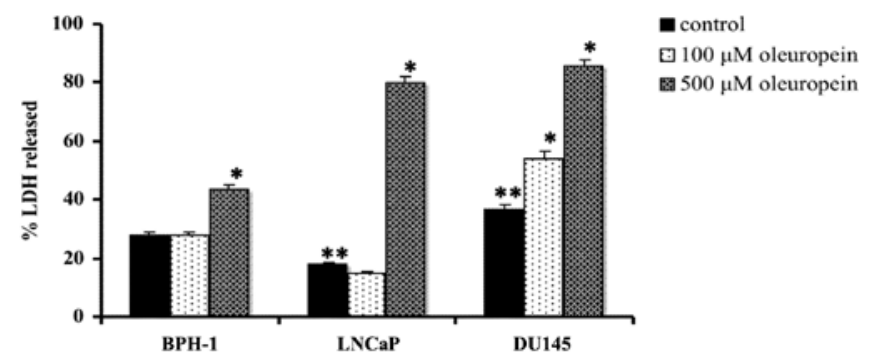

Figure 2. LDH released in BPH-1, LNCaP and DU145 cells untreated and treated for $72 \mathrm{~h}$ with oleuropein at different concentrations $(100-500 \mu \mathrm{M})$. Values represent the means \pm SD of four experiments performed in triplicate. *Significant vs. untreated control cells: $\mathrm{p}<0.001$. * Significant vs. untreated BPH1 cells: $\mathrm{p}<0.005$.

ROS assay. ROS are believed to be involved in cell death induced by a variety of stimuli and some antitumoural agents. Therefore, we tested the hypothesis that oleuropein-induced cell death may be related to an elevation in ROS levels. ROS levels were determined using the fluorescent probe, DCFH-DA. This probe diffuses into the cells, intracellular esterases hydrolyze the acetate groups and the resulting DCFH then reacts with intracellular oxidants resulting in the observed fluorescence.

The intensity of fluorescence was proportional to the levels of intracellular oxidant species. As shown in Fig. 3, 72-h exposure of BPH-1 cells to both 100 or $500 \mu \mathrm{M}$ oleuropein resulted in a significant decrease in ROS levels. No change in ROS production was observed in the LNCaP cells under the same experimental conditions.

However, when DU145 cells were treated with 100-500 $\mu \mathrm{M}$ oleuropein for $72 \mathrm{~h}$, the fluorescence intensity significantly increased with respect to the untreated cells.

Thiol groups $(R S H)$. As thiols represent an important defence against oxidative stress, the determination of non-proteic thiol groups was carried out in order to confirm the involvement of radical/oxidative species in the oleuropein action mechanism.

Untreated LNCaP and DU145 cells showed higher levels of thiol groups than BPH-1 cells (Fig. 4). The treatment of BPH-1 cells with oleuropein resulted in a significant, dose-dependent increase in the levels of thiol groups. A similar, although less marked, increase was observed in LNCaP cells.

The effect of oleuropein on DU145 cells consisted of a significant increase in RSH levels at $100 \mu \mathrm{M}$ oleuropein but, 


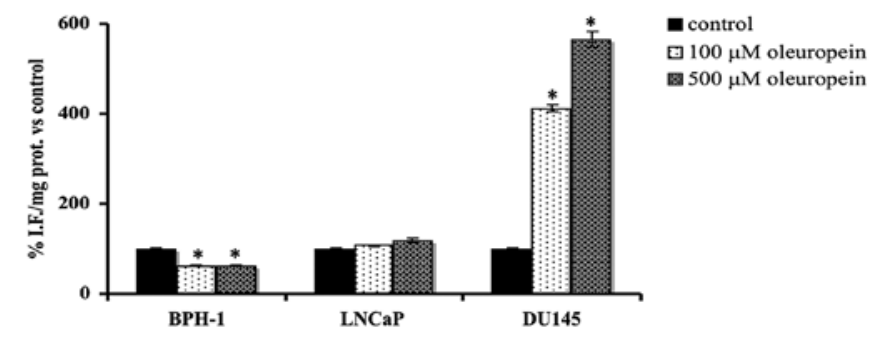

Figure 3. Intracellular oxidants in BPH-1, LNCaP and DU145 cells untreated and treated for $72 \mathrm{~h}$ with oleuropein at different concentrations $(100-500 \mu \mathrm{M})$. Values represent the means \pm SD of four experiments performed in triplicate. *Significant vs. untreated control cells: $\mathrm{p}<0.001$.

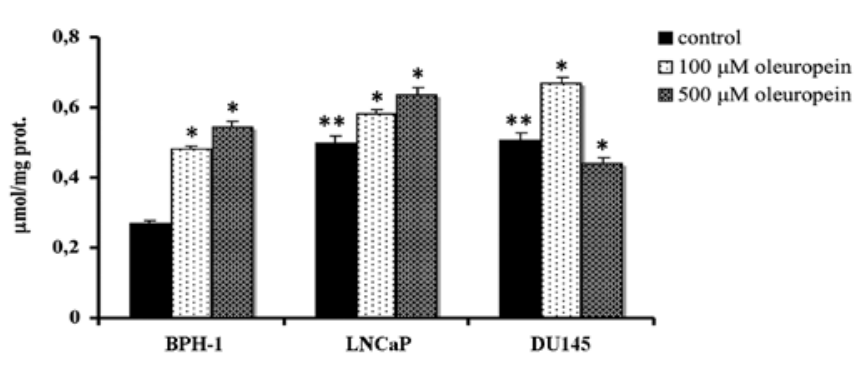

Figure 4. Thiol groups in BPH-1, LNCaP and DU145 cells untreated and treated for $72 \mathrm{~h}$ with oleuropein at different concentrations $(100-500 \mu \mathrm{M})$. Thiol groups are expressed as $\mu \mathrm{mol} / \mathrm{mg}$ protein. Values represent the means \pm SD of four experiments performed in triplicate. *Significant vs. untreated control cells: $\mathrm{p}<0.001 .{ }^{* *}$ Significant vs. untreated BPH1 cells: $\mathrm{p}<0.001$

unlike BPH-1 and LNCaP cells, exposure of DU145 cells to $500 \mu \mathrm{M}$ oleuropein for $72 \mathrm{~h}$ led to a significant decrease in RSH levels (Fig. 4).

HO-1 expression by ELISA. The expression of the enzymatic protein, HO-1, was investigated in BPH-1, LNCaP and DU145 cells using an ELISA kit. The results are reported in Table I. BPH-1 cells showed basal levels lower than those in LNCaP and DU145 cells.

In BPH-1 cells the addition of both $100 \mu \mathrm{M}$ and $500 \mu \mathrm{M}$ oleuropein resulted in the upregulation of HO-1 protein. The treatment of LNCaP cells with 100-500 $\mu \mathrm{M}$ oleuropein resulted in a significant increase in HO-1 expression; by contrast, oleuropein caused a significant decrease in $\mathrm{HO}-1$ protein expression in DU145.

$\gamma$-GCS determination. Western blot analysis carried out on cell lysates showed that untreated BPH-1 and LNCaP cells exhibited very low levels of $\gamma$-GCS, contrary to DU145 cells where the enzyme was more expressed (Fig. 5). The $\gamma$-GCS expression was not modified in the oleuropein-treated DU145 cells.

$p$-Akt/PKB measurements. In the oleoropein-treated BPH-1, LNCaP and DU145 cells, p-Akt(Thr308) and p-Akt (Ser473) were significantly reduced with respect to the control cells. This reduction was more evident in the DU145 cells (Table II). In
Table I.HO-1 levels in BPH-1,LNCaP and DU145 cells untreated and treated with oleuropein at different concentrations.

\begin{tabular}{|c|c|c|}
\hline Cell type & Treatment & $\begin{array}{c}\mathrm{HO}-1 \\
\mathrm{ng} / \mathrm{mg} \text { protein }\end{array}$ \\
\hline \multirow[t]{3}{*}{ BPH-1 } & Control & $1.021 \pm 0.008$ \\
\hline & ${ }^{\text {a} O l e u r o p e i n ~} 100 \mu \mathrm{M}$ & $1.936 \pm 0.003$ \\
\hline & a Oleuropein $500 \mu \mathrm{M}$ & $3.456 \pm 0.006$ \\
\hline \multirow[t]{3}{*}{ LNCaP } & ${ }^{\mathrm{b}}$ Control & $3.215 \pm 0.002$ \\
\hline & a Oleuropein $100 \mu \mathrm{M}$ & $6.631 \pm 0.001$ \\
\hline & 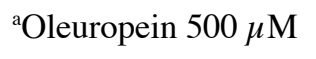 & $11.132 \pm 0.006$ \\
\hline \multirow[t]{3}{*}{ DU145 } & ${ }^{\mathrm{b}}$ Control & $14.461 \pm 0.004$ \\
\hline & ${ }^{\text {a}}$ Oleuropein $100 \mu \mathrm{M}$ & $11.321 \pm 0.007$ \\
\hline & ${ }^{\mathrm{a} O}$ Oleuropein $500 \mu \mathrm{M}$ & $8.475 \pm 0.003$ \\
\hline
\end{tabular}

HO-1 levels in BPH-1, LNCaP and DU145 cells untreated and treated for $72 \mathrm{~h}$ with oleuropein at different concentrations (100-500 $\mu \mathrm{M})$. Results are expressed as $\mathrm{ng} / \mathrm{mg}$ proteins. Values represent the means $\pm \mathrm{SD}$ of four experiments performed in triplicate. ${ }^{\text {aSignificant vs. }}$ untreated control cells: $\mathrm{p}<0.001$. ${ }^{\mathrm{b}}$ Significant vs. untreated BPH1 cells: $\mathrm{p}<0.001$.

addition, these cells showed higher basal levels of p-Akt(Thr308) and p-Akt(Ser473) than the BPH-1 and LNCaP cells.

\section{Discussion}

In recent years, the anti-cancer effects of a variety of bioactive food components have become the focus of a great deal of attention in cancer research, owing primarily to their potential cancer-preventive properties.

Prostate cancer is the sixth most common cancer worldwide, the third most common cancer in men, and the second leading cause of cancer-related mortality in men in Western countries (30). Approximately $80-90 \%$ of prostate cancers are androgen-dependent at initial diagnosis. Both androgen and androgen receptor (AR) are recognized risk factors in the development of prostate cancer $(31,32)$. These observations are further corroborated by genetic evidence from transgenic mouse models suggesting that increased AR signaling in the prostate is linked to an increase in pre-cancerous lesions (33). Since an elevated level of androgen causes an enhancement of prostate cancer, the reduction of circulating levels of androgens is a key to the treatment of prostate cancer $(31,34,35)$. Androgen ablation therapy ultimately fails, and prostate cancer progresses to a hormone refractory state. As regards metastatic disease, few curative therapies currently exist, and treatment generally has been palliative (30). Relapse and metastases occur frequently and in general, are unresponsive to conventional therapy. Therefore, novel approaches are required to treat advanced prostate cancer and the identification of bioactive compounds with the ability to suppress prostate cancer growth promises to be an effective strategy for the therapy of this disease. A significant proportion of cancers are believed to be preventable. It is estimated that one-third of all cancers are preventable simply through modification of diet, maintenance of optimum body 
Table II. p-Akt(Thr308) and p-Akt(Ser473) activity in BPH-1, LNCaP and DU145 cells untreated and treated with oleuropein.

\begin{tabular}{lllc}
\hline Cell type & \multicolumn{1}{c}{ Treatment } & $\begin{array}{c}\text { Akt(Ser473) } \\
\text { U/ng total Akt }\end{array}$ & $\begin{array}{c}\text { Akt(Thr308) } \\
\text { U/ng total Akt }\end{array}$ \\
\hline BPH-1 & Control & $0.079 \pm 0.006$ & $0.95 \pm 0.016$ \\
& Oleuropein $500 \mu \mathrm{M}$ & $0.060 \pm 0.003^{\mathrm{a}}$ & $0.43 \pm 0.023^{\mathrm{a}}$ \\
LNCaP & Control & $0.098 \pm 0.0018$ & $0.80 \pm 0.018$ \\
& Oleuropein $500 \mu \mathrm{M}$ & $0.082 \pm 0.0031^{\mathrm{a}}$ & $0.62 \pm 0.011^{\mathrm{a}}$ \\
DU145 & Control & $0.117 \pm 0.005^{\mathrm{b}}$ & $2.53 \pm 0.03^{\mathrm{b}}$ \\
& Oleuropein $500 \mu \mathrm{M}$ & $0.075 \pm 0.008^{\mathrm{a}}$ & $1.01 \pm 0.022^{\mathrm{a}}$ \\
\hline
\end{tabular}

p-Akt(Thr308) and p-Akt(Ser473) activity in BPH-1,LNCaP and DU145 cells untreated and treated for $72 \mathrm{~h}$ with oleuropein. Results are expressed as U/ng total Akt. Values represent the means \pm SD of four experiments performed in triplicate. aSignificant vs. untreated control cells: $\mathrm{p}<0.001$.

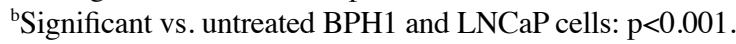

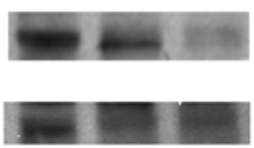

BPH-1

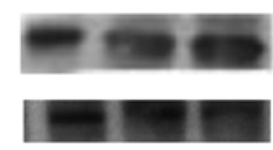

LNCaP

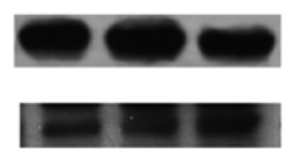

DU145

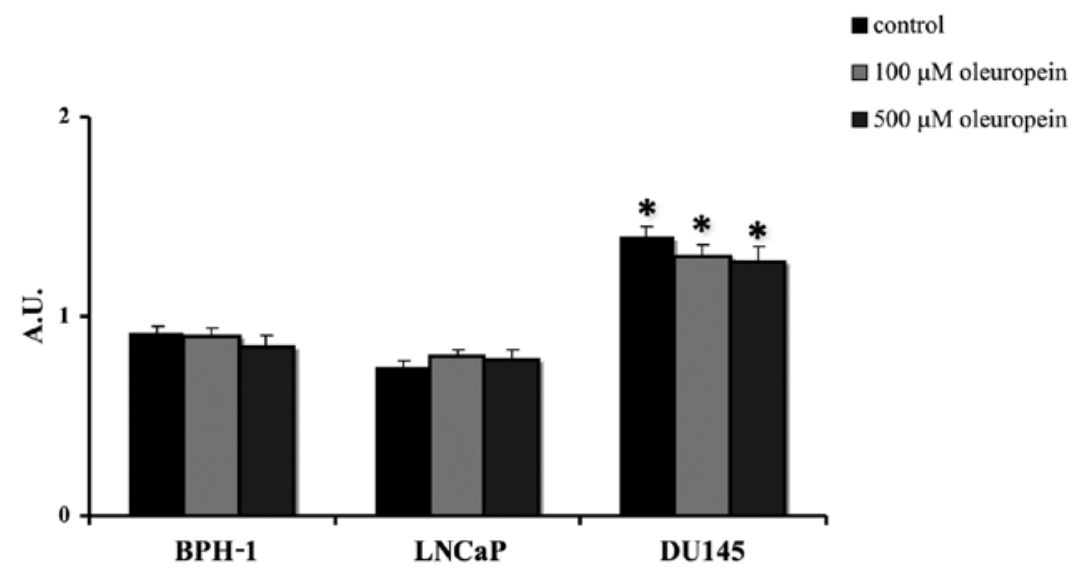

Figure 5. Immunoblotting of $\gamma$-GCS levels in BPH-1, LNCaP and DU145 cells untreated and treated for $72 \mathrm{~h}$ with oleuropein at different concentrations $(100-500 \mu \mathrm{M})$. Values are expressed as densitometric units corresponding to signal intensity present on autoradiographs. Values represent the means \pm SD of

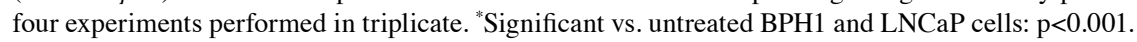

weight, and regular physical activity $(36,37)$. The vast structural diversity of natural compounds found in plants, provides unique opportunities for discovering new drugs that rationally target the abnormal molecular and biochemical signals leading to cancer.

Previous studies on ethnomedicine, together with extensive laboratory findings, have indicated that flavonoids and triterpenic compounds play an important role in the prevention and treatment of cancer (38). Some phenolic compounds and natural triterpenoids such as oleanolic, betulinic and ursolic acids have shown notable effects in suppressing tumourigenesis, as well as in inhibiting tumours (37-40). Many nutritional and non-nutritional phytochemicals with diverse biological proper- ties have shown promise in the prevention and/or treatment of prostate cancer (41).

In recent years, there has been great interest in the health effects of various herbal teas. The olive leaf is one of the most common, traditional herbal teas used among Mediterranean people to cure certain diseases. These properties are attributed to the natural compounds contained in olive leaves.

It is reasonable to hypothesize that some of the phenolic compounds present in olive oil, which have been shown to afford considerable protection against aging, coronary heart disease and cancer by inhibiting, for instance, oxidative stress, may also exhibit anti-cancer effects $(42,43)$. It has been reported that oleuropein, the most abundant polyphenol in olive leaves, 
is a potent antioxidant endowed with anti-inflammatory and anti-neoplastic properties.

The anticancer properties of oleuropein have been confirmed in vitro on different cancer cell lines. In agreement with these studies, our results show that oleuropein decreases prostate cancer cell proliferation and induces necrotic cell death (Fig. 1). The cytotoxic activity of oleuropein was particularly evident in LNCaP and DU145 cells. In these same cell lines, a significant increase in $\mathrm{LDH}$ release after $72 \mathrm{~h}$ of exposure at the highest dose of oleuropein (500 $\mu \mathrm{M})$ was observed (Fig. 2). These data are in agreement with those from other studies and confirm the involvement of oxidative stress in the oleuropein toxicity $(44,45)$. In addition, our results suggest that DU145 cells show a different susceptibility to necrosis induced by oleuropein. This compound induces approximately $50 \%$ of $\mathrm{LDH}$ release even at concentrations of $100 \mu \mathrm{M}$. The measurement of ROS was undertaken in order to examine the role of oxidative stress in the oleuropein mechanism of action.

Certain studies have demonstrated that phenolic compounds with high reducing ability can not only be antioxidants but also pro-oxidants, thus generating ROS (46). It is interesting to note that many human cancer cell types exist in a highly oxidative state due to decreased antioxidant protective enzyme levels compared to their normal tissue counterparts. Thus, cancer cells may be more sensitive to ROS generation within the cells. In our study, we observed that LNCaP and DU145 cells showed basal levels of ROS higher than those in BPH-1 cells (Fig. 3). In BPH-1 cells oleuropein induced a significant reduction in ROS levels, while oleuropein did not cause any effect on LNCaP cells. In DU145 cells, oleuropein caused a significant dose-dependent increase in the levels of ROS. These results suggest that oleuropein behaves as an antioxidant in BPH-1 cells and as pro-oxidant in neoplastic cells.

The antioxidant activity of oleuropein in BPH-1 cells was confirmed by the results obtained from the thiol group determination. In BPH-1 cells, this phenolic compound induced a significant dose-dependent increase in RSH levels; a similar, but less marked, increase was observed in LNCaP cell lines. In addition, we observed that $500 \mu \mathrm{M}$ oleuropein reduced RSH groups in DU145 cells in a dose-dependent manner (Fig. 4). This duality of action suggests that the antioxidant action of oleuropein is not direct, but rather that its action is mediated by other intracellular factors inducible only in benign cells.

It has been reported that the prolonged activation of inflammatory cells generates ROS which can damage host DNA and tissues and contribute to carcinogenesis (47). However the mechanisms of carcinogenesis associated with infection and inflammation have not been fully elucidated. Three main mechanisms have been proposed to account for infectionassociated carcinogenesis: i) direct action of the infectious agent on host cells or tissues; ii) immunosuppression; and iii) elevated production of ROS. Inflammation then facilitates the initiation of normal cells and their growth and the progression to malignancy through the production of inflammatory oxidants inducing oxidative stress. It is known that persistent oxidative stress within carcinoma cells may be responsible for the activation of growth-promoting signaling pathways and increased resistance to apoptosis (48).

In this study, we also evaluated the expression of HO-1, one of the most effective mechanisms for cellular protection against oxidative stress. HO-1, the rate limiting enzyme of heme catabolism, is a powerful antioxidant enzyme. The expression of HO-1 is increased by redox signals such as heme, UV radiation, heavy metals, cytokines and ROS $(49,50)$. By contrast, an increase in thiols and antioxidants inhibits the transcription of the HO-1 gene (51).

The role of HO-1 in cancer biology is far from being completely understood. In cancer, HO-1 has been described as a pro-tumoural molecule due to its antiapoptotic effects on colon cancer and hepatoma on murine models and its proangiogenic effects in human pancreatic cancer $(52,53)$. By contrast, in human tongue cancer, low HO-1 expression has been associated with an increased risk of developing lymph node metastasis (54).

In our study, we observed a different expression of HO-1 in untreated BPH-1, LNCaP and DU145 cells, with a higher expression of this protein in cancerous cells than in BPH-1 cells. Of particular relevance is the different effect elicited by the treatment with oleuropein: a significant increase in $\mathrm{HO}-1$ expression was observed in BPH-1 cells treated with $500 \mu \mathrm{M}$ oleuropein while this increase was absent in DU145 cells (Table I).

These results confirm that in BPH-1 cells the antioxidant activity of oleuropein is due to its ability to induce the expression of HO-1 and also to increase RSH levels (55). This effect has also been reported for other polyphenolic compounds and seems to be due not only to their chemical reactivity toward free radicals and their capacity to prevent the oxidation of important intracellular components, but also to their ability to act as transcription factors, operating on the promoter of the area referred to as 'antioxidant responsive element' (ARE) $(55,56)$. ARE is present in the promoter region of genes encoding antioxidant enzymes, such as HO-1, glutathione-S-transferase, $\gamma$-GCS and NADPH quinone oxidoreductase-1 (57).

The results reported in this study demonstrate that, when added to the culture medium of cancer cells, oleuropein behaves as a pro-oxidant, due to different promoter accessibility/susceptibility or, alternatively, as these cells, in which HO-1 is already overexpressed under normal conditions, would not be able to further respond to stressful oxidative stimuli.

It is known that $\gamma$-GCS can be considered one of the major antioxidant enzymes, as it is the rate-limiting enzyme in reduced gluthatione synthesis. The connection between $\gamma$-GCS and neoplastic transformation has been highlighted in a number of experimental models of chemical carcinogenesis in laboratory animals. However, the mechanisms underlying the increased $\gamma$-GCS expression induced by carcinogenic treatments are not clearly understood (58). The expression of $\gamma$-GCS in cancer cells may represent an important factor in the appearance of a more aggressive and resistant phenotype. In agreement with these studies, we observed that DU145 cells showed higher basal levels of $\gamma$-GCS protein than BPH-1 and LNCaP cells. Furthermore, the expression of $\gamma$-GCS was not modified in oleuropein-treated DU145 cells (Fig. 5) and this phenomenon may correlate with the ability of oleuropein to act on ROS generation rather than on the synthesis of glutathione.

A number of chemopreventive agents including lycopene, soy isoflavones, green tea polyphenols and curcumin have shown inhibitory activities on prostate carcinogenesis through the regulation of major cell signaling pathways, such as the ARs, $\mathrm{NF}-\kappa \mathrm{B}, \mathrm{Wnt}, \mathrm{Hh}$, Notch and Akt (38). Studies have shown that 
Akt can phosphorylate the AR at Ser-210/213 and Ser-790/791, and transactivate the activity of AR independent of androgen signaling (59). The phosphorylation of Akt also sensitizes the AR to low circulating androgen levels, such as those present during maximum androgen blockade (60). This sensitization allows low levels of androgens to induce phosphorylation at specific sites, which is required for the translocation of the AR to the nucleus. Therefore, Akt is an important activator of the AR, which is required for the androgen-independent survival and growth of prostate cancer cells.

To elucidate clearly the functions of oleuropein, we also evaluated the Akt signaling pathway. Cancer cells are known to have alterations in multiple cellular signaling pathways. In prostate cancer cells, the altered proteins produced as a result of gene mutations or defects affect the way these cells communicate with each other. Alterations in cellular signaling pathways can occur at different stages of prostate cancer from early to advanced disease. It has been reported that Akt is activated by phospholipid binding and phosphorylation at Thr-308 by phosphoinositide-dependent protein kinase-1 and at Ser-473 by phosphoinositide-dependent protein kinase-2 (61). Activated Akt promotes cell survival by inhibiting apoptosis through the inactivation of several pro-apoptotic factors including Bad, Forkhead transcription factors, and caspase- $9(62,63)$. Our results demonstrated that the oleuropein treatment of BPH-1, LNCaP and DU145 cells significantly reduced pAkt(Ser473) and Akt(Thr308) (Table II). In addition, we observed that DU145 cells showed higher basal levels of pAkt(Ser473) and Akt(Thr308) than BPH-1 and LNCaP cells. Therefore, oleuropein can induce apoptosis through the downregulation of pAkt, suggesting an inhibitory effect on Akt signaling. These results are consistent with previous studies showing that natural antioxidants could induce apoptosis through the regulation of Akt (64). As with other natural agents which target multiple pathways, oleuropein treatment could be useful both for the prevention of tumour progression and/or therapy, either alone or in combination with conventional preventive or therapeutic agents for the prevention and/or treatment of prostate cancer. However the selectivity of action of oleuropein which allows it to discriminate between cancer and normal cells renders it a very useful tool in the treatment of prostatitis and in preventing the transformation of hypertrophic into cancerous cells, further supporting the growing body of data confirming the bioactivity of natural compounds and their potential use in cancer therapy.

\section{Acknowledgements}

The authors would like to thank Dr M. Wilkinson (Research Assistant) for proofreading the manuscript.

\section{References}

1. Han J, Talorete TP, Yamada P and Isoda H: Anti-proliferative and apoptotic effects of oleuropein and hydroxytyrosol on human breast cancer MCF-7 cells. Cytotechnology 59: 45-53, 2009.

2. Tripoli E, Giammanco M, Tabacchi G, Di Majo D, Giammanco S and La Guardia M: The phenolic compounds of olive oil: structure, biological activity and beneficial effects on human health. Nutr Res Rev 18: 98-112, 2005.

3. Block G, Patterson B and Subar A: Fruit, vegetables, and cancer prevention: a review of the epidemiological evidence. Nutr Cancer 18: 1-29, 1992.
4. Reddy L, Odhav B and Bhoola KD: Natural products for cancer prevention: a global perspective. Pharmacol Ther 99: 1-13, 2003.

5. Carvalho M, Ferreira PJ, Mendes VS, Silva R, Pereira JA, Jerónimod C and Silva BM: Human cancer cell antiproliferative and antioxidant activities of Juglans regia L. Food Chem Toxicol 48: 441-447, 2010.

6. Silva BM, Andrade PB, Valentão P, Ferreres F, Seabra RM and Ferreira MA: Quince (Cydonia oblonga Miller) seed (pulp, peel, and seed) and jam: antioxidant activity. J Agric Food Chem 52: 4705-4712, 2004

7. Giada ML and Filho JM: The importance of dietary phenolic compounds in the promotion of human health. Biol Health Sci 12: 7-15, 2006

8. Owen RW, Giacosa A, Hull WE, Haubner R, Spiegelhalder B and Bartsch $\mathrm{H}$ : The antioxidant/anticancer potential of phenolic compounds isolated from olive oil. Eur J Cancer 36: 1235-1247, 2000.

9. Owen RW, Giacosa A, Hull WE, Haubner R, Wurtele G, Spiegelhalder B and Bartsch H: Olive-oil consumption and health: the possible role of antioxidants. Lancet Oncol 1: 107-112, 2000.

10. El SN and Karakaya S: Olive tree (Olea europaea) leaves: potential beneficial effects on human health. Nutr Rev 67: 632-638, 2009.

11. Visioli F and Galli C: Antiatherogenic components of olive oil. Curr Atheroscler Rep 3: 64-67, 2001.

12. Martin-Moreno JM, Willett WC, Gorgojo L, Banegas JR, Rodriguez-Artalejo F, Fernandez-Rodriguez JC, Maisonneuve P and Boyle P: Dietary fat, olive oil intake and breast cancer risk. Int J Cancer 58: 774-780, 1994.

13. Corona $G$, Deiana $M$, Incani $A$, Vauzour D, Dessì MA and Spencer JP: Inhibition of p38/CREB phosphorylation and COX-2 expression by olive oil polyphenols underlies their anti-proliferative effects. Biochem Biophys Res Commun 362: 606-611, 2007.

14. la Vecchia C, Negri E, Franceschi S, Decarli A, Giacosa A and Lipworth L: Olive oil, other dietary fats, and the risk of breast cancer (Italy). Cancer Causes Control 6: 545-550, 1995.

15. Gordon MH, Paiva-Martins F and Almeida M: Antioxidant activity of hydroxytyrosol acetate compared with that of other olive oil polyphenols. J Agric Food Chem 49: 2480-2485, 2001.

16. Ferreira ICF, Barros L, Soares ME, Bastos ML and Pereira JA: Antioxidant activity and phenolic contents of Olea europaea $L$. leaves sprayed with different copper formulations Isabel. Food Chem 103: 188-195, 2007.

17. Perona JS, Cabello Moruno R and Ruiz-Gutierrez V: The role of virgin olive oil components in the modulation of endothelial function. J Nutr Biochem 17: 429-445, 2006.

18. Benavente Garcia J, Castillo J, Lorente A, Ortuno A and Del Rio JA: Antioxidant activity of phenolics extracted from Olea europaea L. leaves. Food Chem 68: 457-462, 2000.

19. Visioli F, Poli A and Gall C: Antioxidant and other biological activities of phenols from olives and olive oil. Med Res Rev 22: $65-75,2002$.

20. Al-Azzawie HF and Alhamdani MS: Hypoglycemic and antioxidant effect of oleuropein in alloxan-diabetic rabbits. Life Sci 78: 1371-1377, 2006.

21. Somova LI, Shode FO, Ramnanan P and Nadar A: Antihypertensive, antiatherosclerotic and antioxidant activity of triterpenoids isolated from Olea europaea, subspecies africana leaves. J Ethnopharmacol 84: 299-305, 2003.

22. Hamdi $\mathrm{K}$ and Castellon R: Oleuropein, a non-toxic olive iridoid, is an anti-tumor agent and cytoskeleton disruptor. Biochem Biophys Res Commun 334: 769-778, 2005.

23. Fabiani R, De Bartolomeo A, Rosignoli P, Servili M, Selvaggini R, Montedoro GF, Di Saverio C and Morozzi G: Virgin olive oil phenols inhibit proliferation of human promyelocytic leukemia cells (HL60) by inducing apoptosis and differentiation. J Nutr 136: 614-619, 2006.

24. Acquaviva R, Campisi A, Murabito P, Raciti G, Avola R, Mangiameli S, Musumeci I, Barcellona ML, Vanella A and Li Volti G: Propofol attenuates peroxynitrite-mediated DNA damage and apoptosis in cultured astrocytes: an alternative protective mechanism. Anesthesiology 101: 1363-1371, 2004.

25. Di Giacomo C, Acquaviva R, Sorrenti V, Vanella A, Grasso S, Barcellona ML, Galvano F, Vanella L and Renis M: Oxidative and antioxidant status in plasma of runners: effect of oral supplementation with natural antioxidants. J Med Food 12: 145-150, 2009.

26. Bradford MM: A rapid and sensitive method for the quantitation of microgram quantities of protein utilizing the principle of protein-dye binding. Anal Biochem 72: 248-254, 1976. 
27. Russo A, Borrelli F, Campisi A, Acquaviva R, Raciti G and Vanella A: Nitric oxide-related toxicity in cultured astrocytes: effect of Bacopa monniera. Life Sci 73: 1517-1526, 2003.

28. Li Volti G, Galvano F, Frigiola A, Guccione S, Di Giacomo C, Forte S, Tringali G, Caruso M, Adekoya OA and Gazzolo D: Potential immunoregulatory role of heme oxygenase-1 in human milk: a combined biochemical and molecular modeling approach. J Nutr Biochem 21: 865-871, 2010.

29. Vivanco I and Sawyers CL: The phosphatidylinositol 3-Kinase AKT pathway in human cancer. Nat Rev Cancer 2: 489-501, 2002.

30. Lassi K and Dawson NA: Emerging therapies in castrate-resistant prostate cancer. Curr Opin Oncol 21: 260-265, 2009.

31. Denis LJ and Griffiths K: Endocrine treatment in prostate cancer. Semin Surg Oncol 18: 52-74, 2000.

32. Heinlein CA and Chang C: Androgen receptor in prostate cancer. Endocr Rev 25: 276-308, 2004.

33. Stanbrough M, Leav I, Kwan PW, Bubley GJ and Balk SP: Prostatic intraepithelial neoplasia in mice expressing an androgen receptor transgene in prostate epithelium. Proc Natl Acad Sci USA 98: 10823-10828, 2001.

34. Chen CD, Welsbie DS, Tran C, Baek SH, Chen R, Vessella R, Rosenfeld MG and Sawyers CL: Molecular determinants of resistance to antiandrogen therapy. Nat Med 10: 33-39, 2004.

35. Hong MY, Seeram NP and Heber D: Pomegranate polyphenols down-regulate expression of androgen-synthesizing genes in human prostate cancer cells overexpressing the androgen receptor. J Nutr Biochem 19: 848-855, 2008.

36. Amin AR, Kucuk O, Khuri FR and Shin DM: Perspectives for cancer prevention with natural compounds. J Clin Oncol 27: 2712-2725, 2009.

37. Sarkar FH, Li Y, Wang Z and Kong D: Novel targets for prostate cancer chemoprevention. Endocr Relat Cancer 17: R195-R212, 2010.

38. Reyes FJ, Centelles JJ, Lupiáñez JA and Cascante M: (2Alpha,3beta)-2,3-dihydroxyolean-12-en-28-oic acid, a new natural triterpene from Olea europea, induces caspase dependent apoptosis selectively in colon adenocarcinoma cells. FEBS Lett 580: 6302-6310, 2006

39. Liu J: Pharmacology of oleanolic acid and ursolic acid. J Ethnopharmacol 49: 57-68, 1995.

40. Murakami S, Takashima H, Sato Watanabe M, Chonan S, Yamamoto K, Saitoh M, Saito S, Yoshimura H, Sugawara K, Yang J, Gao N and Zhang X: Ursolic acid, an antagonist for transforming growth factor (TGF)-beta1. FEBS Lett 566: 55-59, 2004.

41. Nichenametla SN, Taruscio TG, Barney DL and Exon JH: A review of the effects and mechanisms of polyphenolics in cancer. Crit Rev Food Sci Nutr 46: 161-183, 2006.

42. Stark AH and Madar Z: Olive oil as a functional food: epidemiology and nutritional approaches. Nutr Rev 60: 170-176, 2002.

43. Wahle KW, Caruso D, Ochoa JJ and Quiles JL: Olive oil and modulation of cell signaling in disease prevention. Lipids 39: 1223-1231, 2004.

44. Sirianni R, Chimento A, De Luca A, Casaburi I, Rizza P, Onofrio A, Iacopetta D, Puoci F, Andò S, Maggiolini M and Pezzi V: Oleuropein and hydroxytyrosol inhibit MCF-7 breast cancer cell proliferation interfering with ERK1/2 activation. Mol Nutr Food Res 54: 833-840, 2010.

45. Goulas V, Exarchou V, Troganis AN, Psomiadou E, Fotsis T, Briasoulis E and Gerothanassis IP: Phytochemicals in olive-leaf extracts and their antiproliferative activity against cancer and endothelial cells. Mol Nutr Food Res 53: 600-608, 2009.

46. Wlodek L and Steven HZ: Antioxidants, programmed cell death, and cancer. Nutr Res 21: 295-307, 2001.

47. Ohshima H, Tatemichi M and Sawa T: Chemical basis of inflammation-induced carcinogenesis. Arch Biochem Biophys 417: 3-11, 2003.
48. Brown NS and Bicknell R: Hypoxia and oxidative stress in breast cancer. Oxidative stress: its effects on the growth, metastatic potential and response to therapy of breast cancer. Breast Cancer Res 3: 323-327, 2001

49. Choi AM and Alam J: Heme oxygenase-1: function, regulation, and implication of a novel stress-inducible protein in oxidantinduced lung injury. Am J Respir Cell Mol Biol 15: 9-19, 1996.

50. Cantoni L, Rossi C, Rizzardini M, Gadina M and Ghezzi P: Interleukin-1 and tumour necrosis factor induce hepatic haem oxygenase. Feedback regulation by glucocorticoids. Biochem J 279: 891-894, 1991.

51. Camhi SL, Alam J, Wiegand GW, Chin BY and Choi AM: Transcriptional activation of the HO-1 gene by lipopolysaccharide is mediated by $5^{\prime}$ distal enhancers: role of reactive oxygen intermediates and AP-1. Am J Respir Cell Mol 18: 226-234, 1998.

52. Sunamura M, Duda DG, Ghattas MH, Lozonschi L, Motoi F, Yamauchi J, Matsuno S, Shibahara S and Abraham NG: Heme oxygenase-1 accelerates tumor angiogenesis of human pancreatic cancer. Angiogenesis 6: 15-24, 2003.

53. Hill M, Pereira V, Chauveau C, Zagani R, Remy S, Tesson L, Mazal D, Ubillos L, Brion R, Ashgar K, Mashreghi MF, Kotsch K, Moffett J, Doebis C, Seifert M, Boczkowski J, Osinaga E and Anegon I: Heme oxygenase-1 inhibits rat and human breast cancer cell proliferation: mutual cross inhibition with indoleamine 2,3-dioxygenase. FASEB J 19: 1957-1968, 2005.

54. Yanagawa T, Omura K, Harada H, Nakaso K, Iwasa S, Koyama Y, Onozawa K, Yusa H and Yoshida H: Heme oxygenase-1 expression predicts cervical lymph node metastasis of tongue squamous cell carcinomas. Oral Oncol 40: 21-27, 2004.

55. Scapagnini G, Foresti R, Calabrese V, Giuffrida Stella AM, Green CJ and Motterlini R: Caffeic acid phenethyl ester and curcumin: a novel class of heme oxygenase- 1 inducers. Mol Pharmacol 61: 554-561, 2002.

56. Balogun E, Hoque M, Gong P, Killeen E, Green CJ, Foresti R, Alam J and Motterlini R: Curcumin activates the heme oxygenase-1 gene via regulation of $\mathrm{Nrf} 2$ and the antioxidant-responsive element. Biochem J 371: 887-895, 2003.

57. Ma ZC, Hong Q, Wang YG, Tan HL, Xiao CR, Liang QD, Zhang BL and Gao Y: Ferulic acid protects human umbilical vein endothelial cells from radiation induced oxidative stress by phosphatidylinositol 3-kinase and extracellular signal-regulated kinase pathways. Biol Pharm Bull 33: 29-34, 2010.

58. Järvinen KR, Soini Y, Kahlos K and Kinnula VL: Overexpression of gamma-glutamylcysteine synthetase in human malignant mesothelioma. Hum Pathol 33: 748-755, 2002.

59. Wen Y, Hu MC, Makino K, Spohn B, Bartholomeusz G, Yan DH and Hung MC: HER-2/neu promotes androgen-independent survival and growth of prostate cancer cells through the Akt pathway. Cancer Res 60: 6841-6845, 2000.

60. Rochette-Egly C: Nuclear receptors: integration of multiple signaling pathways through phosphorylation. Cell Signal 15: 355-366, 2003

61. Alessi DR, Andjelkovic M, Caudwell B, Cron P, Morrice N, Cohen $\mathrm{P}$ and Hemmings BA: Mechanism of activation of protein kinase B by insulin and IGF-1. EMBO J 15: 6541-6551, 1996.

62. Cardone MH, Roy N, Stennicke HR, Salvesen GS, Franke TF, Stanbridge E, Frisch S and Reed JC: Regulation of cell death protease caspase-9 by phosphorylation. Science 282: 1318-1321, 1998.

63. Brunet A, Bonni A, Zigmond MJ, Lin MZ, Juo P, Hu LS, Anderson $\mathrm{MJ}$, Arden $\mathrm{KC}$, Blenis $\mathrm{J}$ and Greenberg ME: Akt promotes cell survival by phosphorylating and inhibiting a Forkhead transcription factor. Cell 96: 857-868, 1999.

64. Tang FY, Shih CJ, Cheng LH, Ho HJ and Chen HJ: Lycopene inhibits growth of human colon cancer cells via suppression of the Akt signaling pathway. Mol Nutr Food Res 52: 646-654, 2008. 